\title{
articles
}

\section{Quality of psychiatric referrals to secondary-level care}

W Struwig, MB ChB, DMH

P J Pretorius, MB ChB, MMed (Psych)

Department of Psychiatry, Faculty of Health Sciences, University of the Free State, Bloemfontein

Objectives. This study examined the quality of referrals to secondary-level outpatient psychiatric services rendered by the Department of Psychiatry, University of the Free State. Referral letters were evaluated according to specific quality criteria. Aspects that would enable secondary-level doctors to make informed decisions in terms of further management and need for special investigations were specifically considered.

Design. A descriptive study design was used, and convenience sampling included all referrals to the unit over a 6-month period Uune - November 2007). All referral letters were screened according to a checklist designed for this study.

Setting. The study was undertaken at the Psychiatry Outpatient Department of the Pelonomi Provincial Hospital in Bloemfontein, which functions as a secondary-level referral centre for mental health in the southern Free State.

Outcome measures. Descriptive statistics /percentages, means and standard deviations) were used to summarise results.

Results. Two hundred and sixty-three referral letters were included in the study. Less than $20 \%$ of the referral letters included information on previous psychiatric consultations, current psychotropic medication, the outcome of physical examinations, and results of special investigations. Only $17(6 \%)$ referral letters indicated a preliminary diagnosis according to an officially recognised classification system.

Conclusion. There was conclusive evidence that the quality of referrals to the Psychiatry Department was generally inadequate. A need for more effective referral strategies was identified.

Quality of health care is strongly influenced by efficient communication between different levels of care. Appropriate clinical knowledge and skills, guided by clear policies, are essential to this process.' The Free State Province Department of Health has a well developed mental health care policy to support implementation of the Mental Health Care Act. ${ }^{2}$ The policy sets the framework for rendering services according to a decentralised model. Referrals are done in line with the policy from primary to secondary, and secondary to tertiary level. The majority of patients needing psychiatric care are treated at primary level, and patients must pass through a number of filters before being referred to specialised mental health care services. ${ }^{3}$ Primary care practitioners therefore need to have extensive knowledge of various conditions - including psychiatry.

Referrals have considerable implications for patients, the health care system and health care costs. ${ }^{4}$ It is essential to adhere to guidelines for good medical practice during the referral process, as incomplete assessments and poor quality of referral could have detrimental consequences for both the person referring the patient as well as for the practitioner receiving the patient. A recently published case in the Medical Protection Society Casebook illustrates this point clearly. ${ }^{5}$ In this particular incident, which occurred in the UK, a Mental Health Trust was involved in a claim to account for acceptance of a patient without a proper referral, that resulted in poor risk assessment by the receiving doctor. The psychiatric evaluation was further compromised by an incomplete recording of the patient's relevant psychiatric history. The case report concluded that, in the case of referrals, all relevant patient information must be provided by the referring practitioner, including a medical history and information about the patient's clinical status. ${ }^{5}$

Several factors influence the outcome of referrals. ${ }^{3}$ These include characteristics of the patient and health care provider, as well as factors related to the community and health care system. The referral letter is a key instrument to ensure effective communication and seamless continuation of service between primary and secondary care. ${ }^{6}$ Increased health care costs, cost to patients, and poor patient and mental health care practitioner satisfaction rates can be linked to ineffective referrals.? The quantity and quality of information provided by referring practitioners are therefore crucial elements in the effective management of patients. ${ }^{3}$

Assessing the quality of referrals to secondary-level care may help clinicians to identify aspects that need to be attended to in order to optimise the referral process. Consequently, the aim of this study was to evaluate the quality of referrals to secondary-level outpatient psychiatric services rendered by the Department of Psychiatry, University of the Free State (UFS). 


\section{Methods}

The study was approved by the Ethics Committee, Faculty of Health Sciences, UFS. A convenience sample, comprising all referral letters received at Pelonomi Provincial Hospital's psychiatric outpatients department (OPD) during the period June to November 2007, was selected for analysis. Pelonomi Hospital functions as a secondary referral centre for the southern Free State. For this study, referral was defined as all new patients directed to a psychiatrist for any psychiatric indication. Any document containing information about the patient used for the purposes of referral was regarded as a referral letter.

The sample was analysed after capturing data on a checklist that was specifically designed for the study. Elements contained in the checklist were identified from previously published studies as well as those regarded by the authors from clinical experience as important. 8,9

Referral letters were evaluated in terms of legibility, as well as the quality and quantity of the information provided by the referring practitioners. Referrals were scored by using the checklist, and one point was given for every element present (Table I). If all required elements were present, the referral document would have a maximum score of 24 points.

\section{Results}

During the 6-month period of the study, a total of 266 referrals were made to Pelonomi Hospital psychiatric outpatients department. Three referral letters were excluded from the study because of poor legibility. Forty-two (16\%) of the referrals were received from the private sector, $215(81.7 \%)$ from the public sector, and $6(2.3 \%)$ from tertiary psychiatric care.

The majority of patients (76\%) were referred by means of an official generic referral form. Informal referrals (not written on a structured official document designed specifically for purposes of referral) were made in 17\% of cases. Mental Health Care Act forms and other official forms, which were not designed specifically for referral purposes, were used in $2 \%$, and ward consultation forms in $3 \%$ of cases.

Two hundred and one (76.4\%) of the referrals came from all categories of medical practitioners, which included 39 (14.8\%) referrals from general practitioners. Thirty-two (12.2\%) referrals were received from clinical psychologists, 12 (4.6\%) from nursing staff, and $3(1.1 \%)$ from social workers. Fifteen (5.7\%) referral letters did not clearly indicate the professional category of the
Table I. Summary of main criteria contained in the checklist used to evaluate the quality of referral letters

1. Legibility of information (patient information, referring practitioner's information).

2. Name, signature, qualification, contact details of the referring practitioner and the institution from which the patient was referred.

3. Availability of contact details of practitioner at receiving hospital with whom referral had been arranged.

4. Patient name, address and contact details.

5. Provisional diagnosis indicated (according to DSM-IV* or ICD-10 ${ }^{\dagger}$ ).

6. Treatment approaches during the current episode.

7. Clinical history (medical, psychiatric, previous psychiatric consultations, current psychotropic medication).

8. Clinical status (mental status examination, outcome of physical examination, results of special investigations).

9. Reason for consultation.

10. Type of referral letter.

11. Source of referral (private/public/tertiary psychiatric care).

*DSM-IV: Diagnostic and Statistical Manual of Mental Disorders, 4th edition. ${ }^{10}$ ICD-10: International Statistical Classification of Disease and Related Health Problems 10th revision.

referring practitioner. Results on the availability of identifying particulars and contact details of referring practitioners and referred patients are summarised in Table II.

Analysis of communication between levels of care revealed that $75(28.5 \%)$ referrals were pre-arranged with secondarylevel staff, while only $73(27.7 \%)$ of the pre-arranged referrals

Table II. Criteria screened for regarding identification and contact details of referring practitioners and patients

\begin{tabular}{|c|c|c|}
\hline Criteria & $\begin{array}{l}\text { No. of letters } \\
\text { containing } \\
\text { measured criterion } \\
(\mathrm{N}=263)\end{array}$ & $\%$ \\
\hline $\begin{array}{l}\text { Name of referring } \\
\text { professional }\end{array}$ & 248 & 94.3 \\
\hline Signature & 256 & 97.3 \\
\hline Qualifications & 248 & 94.2 \\
\hline Referring institution & 241 & 91.6 \\
\hline $\begin{array}{l}\text { Contact telephone } \\
\text { number }\end{array}$ & 82 & 31.1 \\
\hline Patient name & 260 & 98.8 \\
\hline Patient contact details & 113 & 42.9 \\
\hline
\end{tabular}


indicated the name of the psychiatrist with whom the referral had been arranged. The elements screened for in the referral letters and the results are given in Table III.

The mean overall score of all the referral letters was 12.7 out of a possible maximum score of 24 . The mean checklist scores obtained by the different categories of referring practitioners are shown in Table IV. Standard deviations in the mean scores obtained by the different professional categories showed a degree of variability within the categories.

Table III. Criteria used to screen referral letters regarding patients' medical and psychiatric history

\begin{tabular}{|c|c|c|}
\hline Criteria & $\begin{array}{l}\text { No. of letters } \\
\text { containing } \\
\text { measured } \\
\text { criterion } \\
(N=263)\end{array}$ & $\%$ \\
\hline Medical history & 66 & 25.0 \\
\hline Psychiatric history & 81 & 30.7 \\
\hline $\begin{array}{l}\text { Previous psychiatric } \\
\text { consultations }\end{array}$ & 16 & 6.0 \\
\hline Current medication & 44 & 16.7 \\
\hline Mental status examination & 134 & 50.9 \\
\hline $\begin{array}{l}\text { Outcome of physical } \\
\text { examination }\end{array}$ & 48 & 18.2 \\
\hline $\begin{array}{l}\text { Special investigations } \\
\text { results }\end{array}$ & 40 & 15.2 \\
\hline $\begin{array}{l}\text { Previous treatment } \\
\text { approaches during } \\
\text { current episode }\end{array}$ & 111 & 42.2 \\
\hline Provisional diagnosis & 162 & 61.6 \\
\hline $\begin{array}{l}\text { Diagnosis according to } \\
\text { an official classification } \\
\text { system (DSM-IV* or ICD- } \\
10^{\dagger} \text { ) }\end{array}$ & 17 & 6.5 \\
\hline Indication for referral & 237 & 90.1 \\
\hline \multicolumn{3}{|c|}{$\begin{array}{l}\text { DSM-IV: Diagnostic and Statistical Manual of Mental Disorders } 4 \text { th edition. } \\
\text { ICD-10: International Statistical Classification of Disease and Related Health } \\
\text { roblems, 10th revision." }\end{array}$} \\
\hline
\end{tabular}

\section{Discussion}

Our findings are supported by observations from previous studies reporting the poor quality of referrals to mental health service providers. ${ }^{3,8}$ In our study, less than one-third of referral letters mentioned the patient's past medical $(25.0 \%)$ and psychiatric (30.7\%) history. A mental status examination was reported in $50.9 \%$ of the cases, but comments on the rest of the clinical status (e.g. physical examination and results of special investigations) were mostly absent, with information given in only $18.2 \%$ and $15.2 \%$ of cases, respectively. These findings correspond to results of a study reported by Culshaw et al. ${ }^{12}$

Contact details of the referring practitioner and the patient were omitted in $68.9 \%$ and $57.1 \%$ of letters, respectively. Details of the referring practitioner are crucial for bilateral communication and after-care of the patient. Patient details are essential in a psychiatric setting as many patients are unable to provide critically needed information because of cognitive impairment or disturbances. Consequently, collateral information frequently needs to be obtained from relatives for diagnostic and discharge planning purposes.

As reported previously, ${ }^{13}$ written communication between health care practitioners could be improved by the referring practitioner providing specific elements of the patient's clinical history. Elements of the referral should ideally include the provisional or differential diagnoses, therapeutic approaches attempted to date (medication and dosage), the patient's physical health status, previous psychiatric consultations, and reason for the current referral. ${ }^{8}$ Our findings show that these aspects were severely neglected, with only $6 \%$ of referral letters containing information on previous psychiatric consultations, and $16.7 \%$ on medication currently used by the patient. A provisional diagnosis was made in $61.1 \%$ of cases, while the use of an official classification system such as the DSM-IV or ICD-10 was indicated on only $6.5 \%$ of referral documents.

Table IV. Mean checklist scores obtained by the different professional categories of referring practitioners

\begin{tabular}{|c|c|c|c|}
\hline Referring professionals & $\begin{array}{l}\text { No. of referrals } \\
(\mathrm{N}=236)(\%)\end{array}$ & $\begin{array}{l}\text { Mean score } \\
\text { out of } 24\end{array}$ & SD* \\
\hline Medical practitioners (all categories) & $162(61.6)$ & 12.7 & \pm 2.0 \\
\hline General practitioners & $39(14.8)$ & 12.0 & \pm 1.7 \\
\hline Clinical psychologists & $32(12.2)$ & 13.7 & \pm 2.3 \\
\hline Nursing staff & $12(4.6)$ & 14.9 & \pm 1.7 \\
\hline Social workers & $3(1.1)$ & 12.6 & \pm 1.2 \\
\hline Category unknown & $15(5.7)$ & 10.0 & \pm 1.8 \\
\hline
\end{tabular}


Making use of a structured or standardised referral letter could assist in the reduction of variability in the quantity and quality of information presented in referral letters. ${ }^{8}$ However, 200 (76\%) of the referrals included in this study were done by means of a standardised generic form that is the official form used for referrals made to all disciplines. No significant differences were noted in terms of the quantity of information provided on the standardised form versus informal referral letters. The authors strongly recommend the implementation of a standardised referral form specifically designed for, and focused on, psychiatric referrals. It has been demonstrated that primary care practitioners often fail to appropriately evaluate, diagnose and treat psychiatric disorders or conditions. ${ }^{14} \mathrm{~A}$ standardised referral format, tailor-made for psychiatry, should therefore guide the medical practitioner's approach to the psychiatric patient. ${ }^{15}$

Ineffective referrals have been explained to result from concerns with patient confidentiality and the time-consuming nature of contact by letter. ${ }^{3}$ Our study, however, did not investigate reasons for poor-quality referrals.

Omitting details of the patient's physical status, results of special investigations and treatment history have potential negative implications in terms of patient care, risk assessment, medico-legal liability and increased health care costs. A missed underlying physical condition in a patient presenting with psychiatric symptoms may have adverse consequences for the patient as well as medico-legal implications for both the referring and the receiving practitioners. ${ }^{12}$

Some limitations of the study need to be noted. Only patients with written referrals were included in the study. The checklist used did not differentiate between referrals written on the Department of Health's standard referral form $(\mathrm{H} 3 \mathrm{O} 1)$ and other forms of written referrals. Patients were not exclusively referred from primary care practitioners, but included all referrals to this specific psychiatric outpatient department. Consultation liaison cases and downreferrals from tertiary care were included in the study. The checklist was not designed to differentiate between the quality of downreferrals from tertiary care, and those referred from lower levels of care to Pelonomi OPD.

The evaluation of the standard of risk assessment was not sufficiently investigated in this study. The subgroup of patients where the Mental Health Care Act forms were used as referral correspondence was insufficient in number (2\%). Therefore, it was not possible to draw any conclusions in terms of the quality of referrals from these documents.
Patient satisfaction, which is an important factor in the referral process, was not measured in this study. Furthermore, referral letters were evaluated in terms of the quantity and legibility of the information, but the degree to which the different elements were satisfactorily addressed (e.g. Was a vague or clear indication of the diagnosis given?) was not measured.

\section{Conclusion}

This study assessed the standards of communication between primary and secondary psychiatric services. The authors hope that this study will serve to improve the deficiencies that were identified and to indicate the need to develop practical guidelines regarding referrals to psychiatric departments. Standardisation of referral forms, which are tailor-made for psychiatry, is likely to facilitate the process of effective referrals, with positive effects on patient satisfaction as well as the cost and quality of care.

We thank L M van der Merwe and Johan le Roux for their valuable inputs, and Daleen Struwig, medical writer, Faculty of Health Sciences, UFS, for technical and editorial preparation of the manuscript for publication.

\section{References}

1 Markar T.N. Communications between psychiatrists and general practitioners in learning disability - a clinical audit. Br J Dev Disabil 2002; 95: 107-1 12

2. Mental Health Care Act No. 17 of 2002. Government Gazette 2002; 449(24024). Pretoria: Government Gazette. http://www.info.gov.za/view/DownloaFileAction?id =68051 (accessed 15 November 2008)

3. TanielianTL, Pincus HA, Dietrich AJ, et al. Referrals to psychiatrists. Assessing the communication interface between psychiatry and primary care. Psychosomatics 2000; 41: 245-252.

4. Grimshaw JM, Winkens RA, Shirran L, et al. Interventions to improve outpatient referrals from primary care to secondary care. Cochrane Database Syst Rev 2005; 20: CD005471

5. Medical Protection Society (MPS). Heading for a Fall. http://www. medicalprotection.org/uk/casebook/may2007/case-reports/heading-for-a-fall. (accessed 15 November 2008).

6. Shaw I, Smith KM, Middleton H. Woodward L. A letter of consequence: referral letters from general practitioners to secondary mental health services. Qual Health Res 2005; 15: 116-128.

7. Jones E G, Stott NC. Avoidable referrals? Analysis of 170 consecutive referrals to secondary care. Br Med J 1994; 309: 576-578.

8. Burbach FR, Harding S. GP referral letters to a community mental health team: an analysis of the quality and quantity of information. Int J Health Care Qual Assur 1997; 10: 67-72

9. Blakeley A, Morgan J, Anderson I. Communication between GPs and psychiatrists: the long and short of it. Psychiatr Bull 1997; 21: 622-624.

10. American Psychiatric Association. Diagnostic and Statistical Manual of Mental Disorders, 4th ed, Text Revision. Washington DC: American Psychiatric Association, 2002.

11. International Statistical Classification of Disease and Related Health Problems, 10th revision (ICD-10). Geneva: World Health Organization, 1992.

12. Culshaw D, Clafferty R, Brown K. Let's get physical! A study of general practitioners' referral letters to general adult psychiatry - are physical examination and investigation results included? Scott Med J 2008; 53: 7-8.

13. Lucena RJ, Lesage A. Family physicians and psychiatrists. Qualitative study of physicians' view on collaboration. Can Fam Physician 2002; 48: 923-929.

14. Hodges B, Inch C, Silver I. Improving the psychiatric knowledge, skills, and attitudes of primary care physicians, 1950-2000: a review. Am J Psych 200 1; 158: 15791586.

15. Bronheim HE, Fulop G, Kunkel EJ, et al. The Academy of Psychosomatic Medicine practice guidelines for psychiatric consultation in the general medical setting. Psychosomatics 1998; 39: S8-S30. 